\title{
Un análisis estético-homológico de un artista surrealista contemporâneo
}

\author{
Sandra de Souza Melo \\ Doutorado em Pedagogia \\ Professora Associado 1, UFPE \\ sandra@ufpe.br
}

\begin{abstract}
RESUMEN:
Este trabajo tiene como objetivo un análisis de la pintura de un artista contemporáneo. Marcos Carvalho encuentra en el surrealismo el lenguaje del arte para expresar su creatividad e ideas que según los principios de esta escuela explota el inconsciente, dando riendas sueltas a una efusión de imágenes presentes insólitamente en un mismo escenario. Podemos hablar del análisis de Almeida, Pinho y Melo (1984); França, Barboza y Melo (2003); Cruz y Cavalcanti (2009); Neves y Melo (2013), donde se busca un análisis de la presencia de la homología en obras de arte. Para realizar tal análisis haremos un pequeño histórico de Dalí y su obra; hablaremos del artista Marcos Carvalho, su formación y producción; dedicaremos algunos párrafos a la homología; enseñaremos el análisis estéticohomológico de dos obras surrealistas del artista. Finalmente, presentaremos nuestras conclusiones donde subrayamos la presencia de la homología para equilibrio en la composición de la obra ${ }^{1}$.
\end{abstract}

Palabra clave: surrealismo, homología, pintura, Dalí, Marcos Carvalho.

\section{RESUMO:}

Este trabalho tem como objetivo uma análise da pintura de um artista contemporâneo. Marcos Carvalho encontra no surrealismo a linguagem da arte para expressar sua criatividade e ideias que segundo os princípios desta escola explora o inconsciente, dando liberdade a uma efusão de imagens presentes insolitamente em um mesmo cenário. Podemos falar da análise de Almeida, Pinho e Melo (1984); França, Barboza e Melo (2003); Cruz e Cavalcanti (2009); Neves e Melo (2013), onde se busca uma apreciação da presença da homologia nas obras de arte. Para concretizarmos tal análise faremos um pequeno histórico de Dalí e sua obra; falaremos do artista Marcos Carvalho, sua formação e produção; dedicaremos alguns parágrafos à homologia; realizaremos uma análise estéticohomológica de duas obras surrealistas do artista. Finalmente, apresentaremos nossas conclusões onde destacaremos a presença da homologia para o equilíbrio na composição da obra.

Palavras-chave: surrealismo, homologia, pintura, Dalí, Marcos Carvalho.

\footnotetext{
${ }^{1}$ Este artigo es el resultado del curso Como elaborar un texto académico en Ciencias Sociales impartido por la Universidad Rey Juan Carlos de Madrid nel sitio MIRIADAX.
} 


\section{INTRODUÇÃO}

Este trabajo tiene como objetivo un análisis de la pintura de un artista contemporáneo. El artista elegido encuentra en el surrealismo el lenguaje del arte para expresar su creatividad e ideas que según los principios de esta escuela comenzada por el manifiesto del surrealismo de Breton, explota el inconsciente, dando riendas sueltas a una efusión de imágenes que por la realidad jamás se presentarían juntas en un mismo escenario.

El artista plástico Marcos Carvalho ha elegido este lenguaje como su principal modo de expresión. Pero no se comienza del cero, sino que se conoce e inspirase en otros artistas como un homenaje a su significativa producción y colaboración en un determinado estilo es ya practicado por muchos de los que miran al pasado proyectando luces al futuro.

Así siendo, este artista proyecta luces al futuro echando un vistazo y un justo homenaje a uno de los grandes artistas españoles del surrealismo: Dalí. Este gigante del arte conocido mundialmente sirve de inspiración a muchos de los actuales exponentes de dicho arte contemporánea, moderna, actual.

Pero no solo el arte se mezcla en la composición de pinturas. La matemática en diversas situaciones se encuentra involucrada en las bases de una expresión artística como la música, la pintura, la escultura (TV ESCOLA, TV CULTURA, 2002). Cuando analizamos la matemática inmiscuida en estos ramos del arte, nos damos cuenta de su participación como elemento fundamental en la estética de dichas artes.

Mariotti (2005) subraya como conceptos matemáticos como los de la geometría proyectiva se desarrollaron a partir de los instrumentos creados por los artistas para hacer la representación de sus obras. De ahí, vemos que matemática y arte no son tan lejanas como si pudiese pensar a la ligera, sin un mayor análisis.

Para proceder un análisis de la obra de arte, algunos autores han dedicado su tiempo a definir parámetros que pudiesen ayudar a expertos y laicos. Podemos nombrar Costella (1997), Val Cubero (2010), Muradas (19941995). Estos trabajos tratan de metodologías de análisis como el método iconográfico de Panofsky (1939), el modelo de Pierre Bourdieu, el modelo genealógico, etc. Este abanico de diferentes modelos nos es útil a la hora de profundizar en el campo de análisis de las obras de arte e incluso en el amplio mundo de las imágenes cotidianas. Unos tratan de aspectos más teóricos y densos, otros de aspectos más libres.

Algunos ya emprendieron el camino del análisis de la armonía, de la organización de los elementos presentes en la pintura de artistas de diferentes corrientes de la expresión artística. Podemos hablar del análisis de Almeida, Pinho y Melo (1984) que busca la homología en los cuadros de la artista Lícia Pinho; el trabajo de França, Barboza y Melo (2003) que busca la esencia de las formas en obras de la corriente concreta; Cruz y Cavalcanti (2009) hacen un 
análisis sobre a homología en la obra de Mondrian; del trabajo de Neves y Melo (2013) que analiza la homología en el trabajo de MC Escher; entre otros.

Para realizarnos tal análisis haremos un pequeño histórico de Dalí y su obra; hablaremos del artista Marcos Carvalho, su formación y producción; dedicaremos algunos párrafos a la homología; y finalmente presentaremos el análisis de dos obras surrealistas de Marcos Carvalho.

\section{DESARROLLO}

En los siguientes párrafos nos dedicaremos a presentar un pequeño histórico de Salvador Dalí y su obra; hablaremos del artista Marcos Carvalho, su formación y producción; dedicaremos algunas palabras a la homología.

\subsection{El Surrealismo de Dalí}

Salvador Dalí nace el 11 de mayo de 1904 en Figueras, Girona y desde su infancia, muestra manías y extravagancias de un marcado narcisismo, inclinado a llamar la atención sobre sí mismo. Ya en 1918 algunos de sus cuadros son presentados en una muestra en el teatro municipal de Figueras.

En 1922 el padre del artista decidió matricularle en la Escuela Especial de Pintura, Escultura y Grabado de la Real Academia de Bellas Artes de San Fernando; como tarjeta de presentación, Salvador contaba con la recomendación especial de su maestro Juan Núñez. Llegado a Madrid, Dalí era un muchacho provinciano que creía en el pintor como artista genial como estudiante, fue un alumno trabajador, aplicado, extravagante, pero demuestra precoces dotes de dibujante.

En la Residencia de Estudiantes, donde se alojaba, conoció a Lorca, que le enseñó a tener una opinión moderna sobre los distintos acontecimientos vitales. Es durante estos años en la residencia cuando, junto a los compañeros Lorca, Pepín Bello y Luis Buñuel, desarrolla toda una terminología propia, a base de signos y símbolos que son posteriormente usados en toda su obra (GALA, 1999-2000).

Un ejemplo de su obra durante los años 20 es el cuadro La muchacha a la ventana (Figura 1) que muestra su hermana, Ana María, con la edad de diecisiete años, asomada a una ventana de la casa de vacaciones de los Dalí en Cadaqués. Según Dalí, su fascinación por la espalda femenina se remonta a lejanas impresiones de una infancia rodeada de mujeres (BIBLIOTECA EL MUNDO, 2006). 
Figura 1: Muchacha a la ventana. Óleo sobre lienzo, 1925.

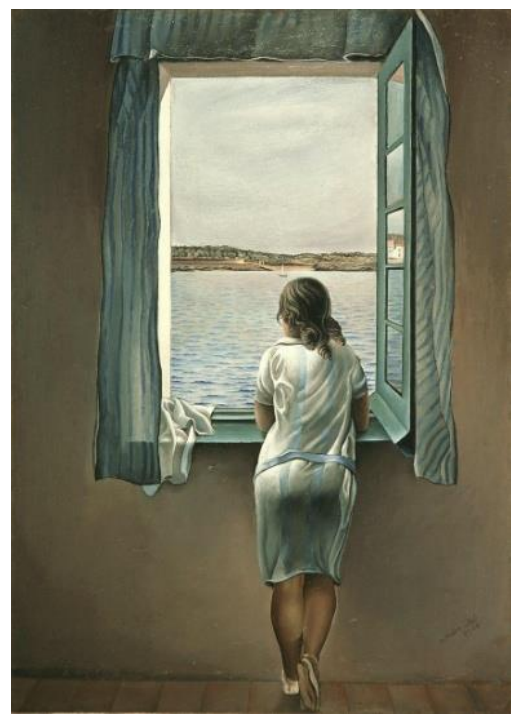

Fonte: http://www.museoreinasofia.es/en/collection/artwork/figura-finestra-figure-window

También en Madrid, él descubrió las ideas de Freud y aprendió en sus libros que el verdadero héroe es el que se enfrenta al padre y lo vence, pues aunque su padre era un libre pensador, se mostraba poco convencido de la carrera que quería emprender su hijo -fue la primera forma de autoridad a la cual se opuso. Su obsesión por el mundo de lo inconsciente comienza en 1922, cuando se publican en español las Obras Completas de Sigmund Freud. Sus teorías del psicoanálisis, que afirman que numerosas voluntades primitivas del hombre se manifiestan a través de los sueños, llevan a Dalí a la creación de obras repletas de escenas oníricas.

En 1924 André Breton publica su Manifiesto surrealista -al que le seguiría, años después, un segundo Manifiesto que en gran medida actualiza el anterior-proclamando la fatiga de todo y defendiendo como salvación del arte el único camino no explorado: el subconsciente con todos sus absurdos, con sus juegos ilógicos, sus obscenidades. Breton decía que es inadmisible que una parte tan considerable de la actividad psíquica haya retenido tan poco la atención de las gentes hasta ahora - el sueño (ALMEIDA, 2013). Al movimiento surrealista le interesa el arte como método para alumbrar misterios de la vida o de los mecanismos psíquicos del hombre.

Cuando se instaló en París (en abril de 1929), conoció al círculo surrealista y a André Breton, del cual posteriormente se alejó para formar su propio y particular estilo, en el que la excentricidad fue una de las formas principales que utilizó para enfrentarse al mundo y a la vida cotidiana.

Además de las pinturas, Dalí fue el más brillante creador de "objetos surrealistas", también conocidos como "objetos de funcionamiento simbólico". El objeto surrealista desafiaba el concepto de realidad exterior y se imponía a los objetos concretos nacidos de la imaginación. Los objetos de Dalí ocupan un lugar destacado en las numerosas exposiciones surrealistas de los años treinta (MUSEO NACIONAL CENTRO DE ARTE - REINA SOFIA, 2013). 
La Guerra Civil española estalla en 1936 y durante una visita a Barcelona, anterior al conflicto, Dalí tuvo que suspender una conferencia anunciada en la librería Catalònia debido a las revueltas callejeras, en las que se enfrentaban los partidarios de la proclamación de la república catalana con los defensores del Gobierno central.

De su producción en los años 30 vemos el cuadro "Huevos al plato sin plato" (Figura 2), donde se vislumbra la tranquila ensenada de Port Lligat al crepúsculo al fondo y se destaca una bandeja con dos huevos fritos, con un tercero colgado encima de ellos, sostenido por un hilo cuyo origen se pierde fuera del espacio pictórico. Para Dalí los huevos simbolizan sobre todo la vida intrauterina y las sensaciones que la acompañan (BIBLIOTECA EL MUNDO, 2006).

Figura 2: Huevos al plato sin plato. Óleo sobre lienzo, 1932.

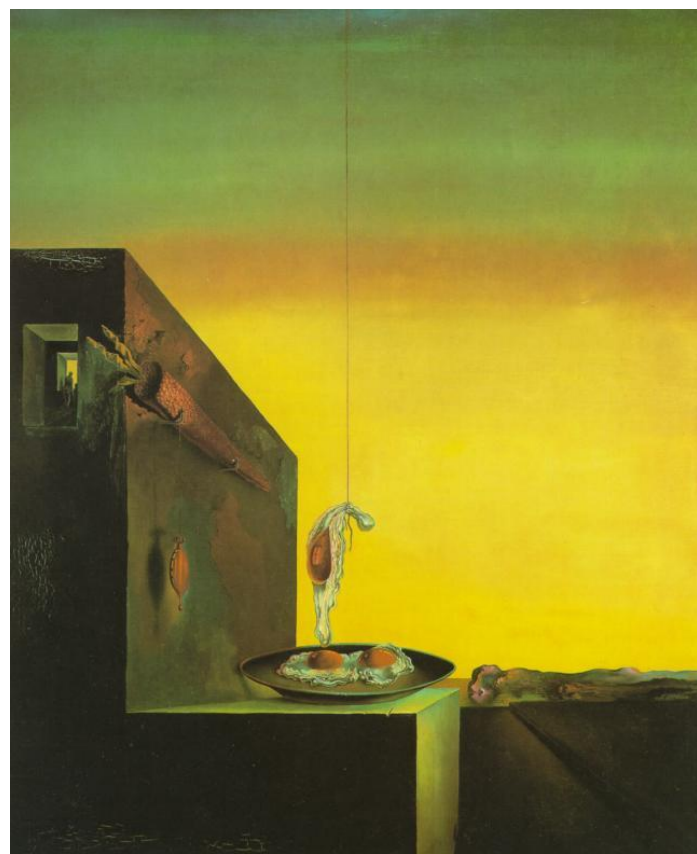

Fuente: The Salvador Dalí Museum -

http://archive.thedali.org/MWEBimages/Collection\%20Images/2000.13_thumbnail.jpg

Aun, según el Dalí Museum (2017): Esta pintura se inspiró inicialmente en lo que Dalí llamó una "memoria intrauterina". De esta experiencia, afirma Dalí, "todo el encanto para mí estaba en mis ojos y la visión más espléndida (mientras estaba en el útero) era la de un par de huevos fritos en una sartén sin sartén [...]". Dalí afirma que podía conjurar esta memoria intrauterina cada vez que lo deseaba aplicando presión con los dedos sobre los ojos, estimulando sus fosfenos para crear imágenes visuales brillantes. En esta pintura, Dalí reproduce los colores que le recuerdan el útero de su madre: "el paraíso intrauterino era el color del infierno [...] rojo, naranja, amarillo y azulado, el color de las llamas [...]" (THE DALÍ MUSEUM, 2017).

Durante la Segunda Guerra Mundial, Dalí se instaló por una larga temporada en Estados Unidos, donde descubrió la verdadera fuerza de la cultura popular. Hace escaparates para grandes almacenes, diseños de 
corbatas, películas para Hollywood, dibujos animados..., y se convierte en el Dalí pop que aparece en anuncios y actúa en televisión. En Nueva York, Dalí intimó con Andy Warhol, asistía a conciertos de David Bowie y le encantaba el maquillaje grotesco de Alice Cooper. En este período empezó a incluir en sus pinturas iconos y figuras mediáticas de este nuevo mundo de la sociedad de masas.

Aun de su producción en los años 30, vemos el cuadro "Jirafa en llamas" (Figura 3), cuyo título haciendo alusión a la jirafa podría guardar relación con el título del tema de una película -jamás realizada que Dalí había escrito en estos años junto con el actor Harpo Marx, Giraffes on Horseback Salad (BIBLIOTECA EL MUNDO, 2006).

Figura 3: Jirafa en llamas. Óleo sobre tabla - 1936-1937

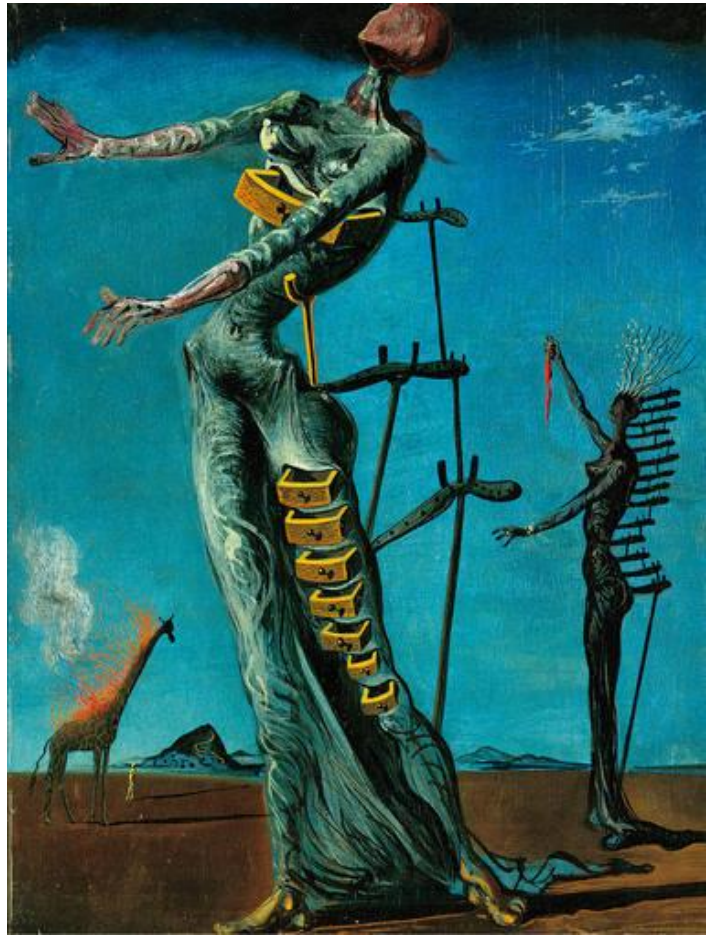

Fuente: Kunstmuseum, Basilea, Suiza,

En 1949 Dalí y Gala vuelven a Europa y en 1951, é redactado el Manifiesto místico, dando inicio al período corpuscular y de la mística nuclear. Aun en los años 50 (1954), rueda la película L'histoire prodigieuse de la Dentellière et du Rhinocéros con dirección artística de Robert Deschames.

En las décadas de 60 y 70 se vuelve cada vez más internacional, ocurriendo en 1971 la inauguración del Salvador Dalí Museum de Cleveland con la colección de E y A. Reynolds Morse, y en 1978 es elegido miembro de la Academia de Bellas Artes de París.

El 10 de junio de 1982, muere Gala. Dalí recibe del rey de España, Juan Carlos, el título de marqués de Púbol, del nombre del castillo que había regalado a Gala. 
En la figura 4, vemos el cuadro Sueño causado por el vuelo de una abeja alrededor de una granada un segundo antes de despertar, de 1944, donde la mujer tendida representa Gala y los animales y demás elementos son mecanismos del sueño con estímulos derivados de los acontecimientos exteriores, que son integrados al contexto (BIBLIOTECA EL MUNDO, 2006). Aun según Alarcó (2017):

“En este sueño, que tiene lugar a plena luz del día, Dalí pretendía, según explicó en 1962, «poner en imágenes por primera vez el descubrimiento de Freud del típico sueño con un argumento largo, consecuencia de la instantaneidad de un accidente que provoca el despertar. Así como la caída de una barra sobre el cuello de una persona dormida provoca simultáneamente su despertar y el final de un largo sueño que termina con la caída sobre ella de la cuchilla de una guillotina, el ruido de la abeja provoca aquí la sensación del picotazo que despertará a Gala»." (ALARCÓ, 2017, sin paginación).

Figura 4: Sueño causado por el vuelo de una abeja alrededor de una granada un segundo antes de despertar. Óleo sobre lienzo, 1944.

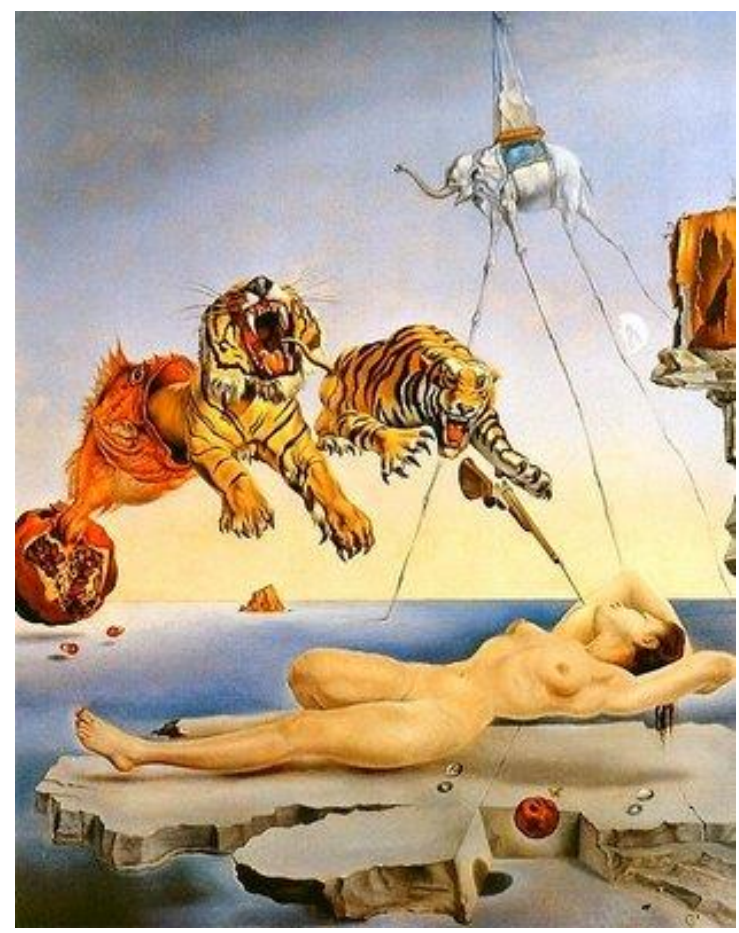

Fuente: https://www.museothyssen.org/coleccion/artistas/dali-salvador/sueno-causado-vueloabeja-alrededor-granada-segundo-antes.

Dalí falleció el 23 de enero de 1989, "el primer día de luna vieja”, tal como había pronosticado su amigo y fiel servidor durante 40 años Arturo Caminada. Los últimos días, semanas y meses de la vida de Dalí fueron retransmitidos al minuto por medios de comunicación de todo el mundo que se hicieron eco de las polémicas sobre el lugar donde iba a ser enterrado, su testamento, los derechos de sus obras y los más mínimos detalles. Es sepultado en la cripta del teatro-museo Dalí, en Figueras. Su heredero universal es el Estado español (LA VANGUARDIA, 2015). 


\subsection{Marcos Carvalho - un surrealista}

Nace en Recife el 29 de diciembre de 1960, hijo de Hélio Cabral de Carvalho y de doña Ana Maria Acioli de Carvalho. En esta misma ciudad el artista vivencia las realidades que van a influenciar sus obras con el comienzo de su formación y producción artística que ocurre en 1980 con el ingreso en la Associação dos Antigos Alunos do Marista - AAAM, teniendo como profesor el artista plástico Jacques Weyne (MELO, 2016; MELO y VIEIRA, 2015, MELO y FILHA, 2015).

Frecuentó el espacio Guainases en el Mercado da Ribeira - Olinda (1984) donde inició su trabajo con litografía, teniendo contacto con varios de los artistas pernambucanos como Gil Vicente, Tereza Costa Rego, Zé de Moura, Maurício Silva entre otros.

Su formación artística ocurrió en el taller del pintor Jacques Weyne en el período que va desde el 1980 a 1986 . En este ambiente de formación tuvo contacto con otros pintores tales como Armando Burlemax, Geraldo Ramos, Virgini, Erasmo Beltrão, Virgilio Ramos, Elias de Paula, Arnaldo Lopes y tantos otros del escenario recifense. Frecuentó en la misma época (1982) el atelier de Cavani Rosas participando del Taller de Dibujo, bajo la orientación de este grande artista pernambucano.

Figura 5: artista Marcos Carvalho, 2014

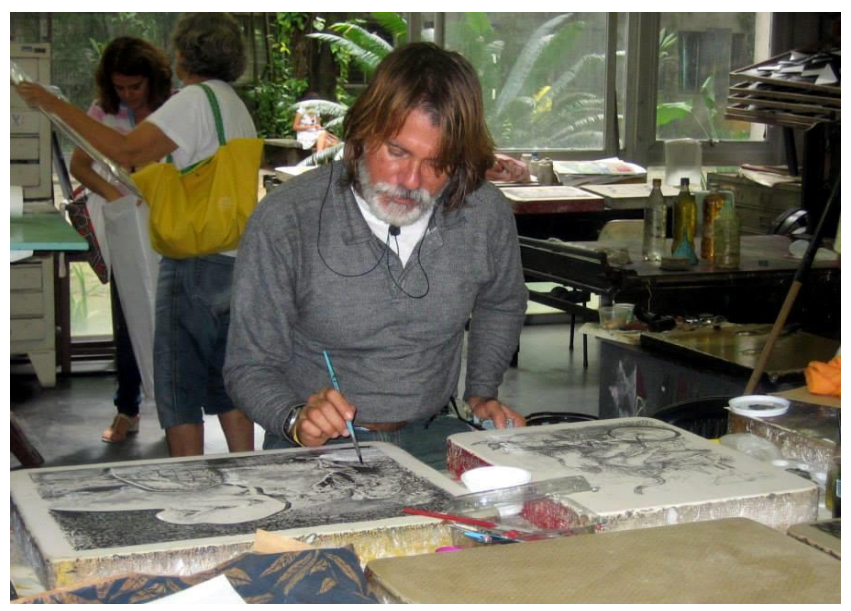

Fuente: Marcos Carvalho, 2013.

En su búsqueda por perfeccionar su lenguaje pictórico y la ampliación de las posibilidades de expresión del arte figurativa, estuvo un período en el Solar do Barão en la ciudad de Curitiba, bajo la orientación del litógrafo Antonio Grosso en el curso de litografía. En este ambiente de formación en las técnicas de la litografía, trabó intercambio de ideas con artistas locales como Carlos Tulio, Denise Romã, Inácio entre otros que influenciaron sus obras y su formación (MELO, 2016). 
Figura 6: obra O impacto da queda nos transformou em luz. Óleo sobre lienzo, 1991.

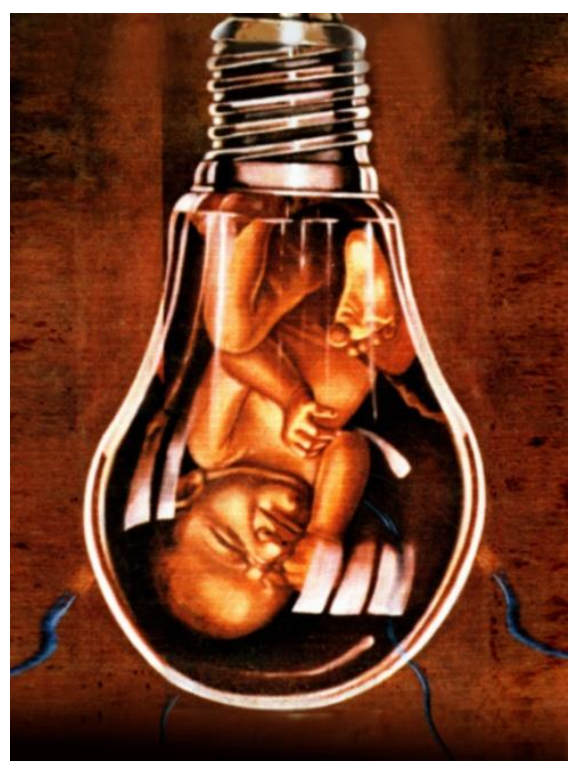

Fuente: Marcos Carvalho, 1991.

Entre sus participaciones en exposiciones individuales y colectivas tenemos: 12 Raizes ao quadro - UFPE (1981); Salão Pirelli - MASP/SP (1983); Coletiva do CAPTA - Túnel de Fuga - Museo da Cidade de Recife - PE (1983); 50 anos do Palácio da Justiça - Recife - PE (1984); Coletiva Mulher, Corpo e Alma Recife - PE (1985); Artes Plásticas nos Correios - Recife - PE; Mostra Surrealista - Galeria de Arte Archidy Picado - Espaço Cultural José Lins do Rego - PB (1986); Exposição de Gravadores Paraenses - Fundação Cultural de MS - MS (1986); Mostra de Gravuras Litográficas - Fundação Solar do Barão - PR (1986); Exposição de Gravuras - Espaço Cultural de Cascavel - PR; Mostra de Artes Itinerante MARCA - Itália (1998); Olhar a ponte que nos liga (2016 - Recife; 2017 - João Pessoa y Salvador); Os tons que pintam o Dom - Coletiva - Editora da UFPE - Recife (2017).

Trabajó durante varios años en oficinas de publicidad como Aporte (1995-98), Ítalo Bianchi (1999-2002) y estos espacios de intercambio entre creadores de imágenes para la publicidad también influencian su obra pictórica. Trabajó en equipo esporádicamente con AMPLA, 3 PONTOS, AGENCIA 1 y ESPHERA DESIGN. Durante este período ideó la estatuilla del Troféu Guerreiro da Luz, entregado como premio de destaque social por el Centro de Integração Empresa Escola - CIEE el año 2000. Sin embargo, durante este período estuvo alejado de exposiciones individuales y colectivas, haciendo trabajos de pintura y escultura bajo encomienda tales como Caboclo de Lança en conmemoración a los 30 años de PHILIPS NORDESTE y en seguida Cavalo Marinho (MELO y FILHA, 2015). 
Figura 7: artista en 2002 con la escultura Caboclo de Lança.

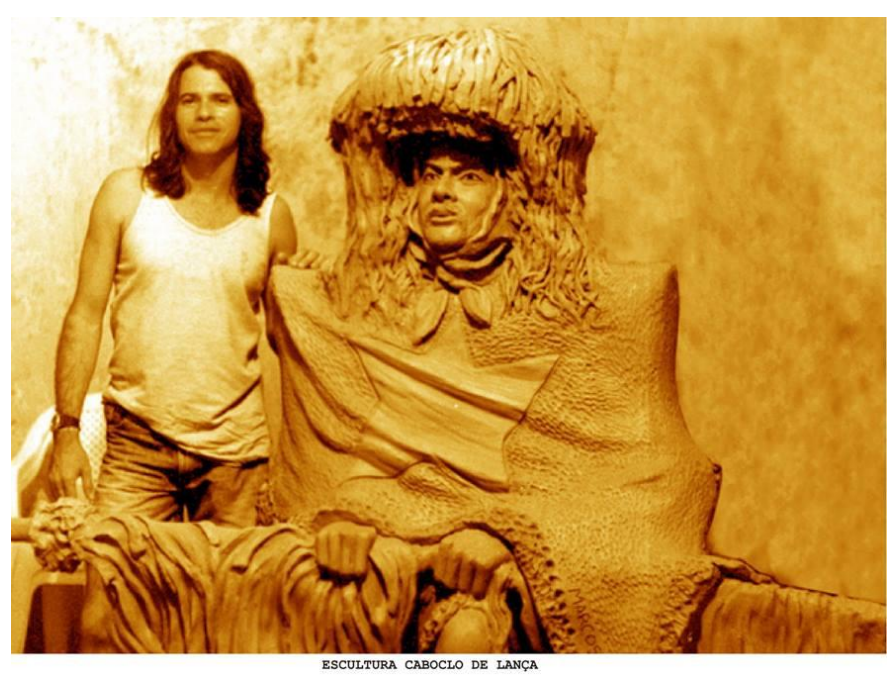

Fuente: Marcos Carvalho, 2002.

Con la experiencia adquirida en los varios trabajos realizados en escultura, tuvo la oportunidad de dedicarse a la restauración de obras escultóricas de varios dos artistas pernambucanos. Dentro de estos trabajos se puede destacar la restauración realizada el 2013 de más de 20 obras de escultura ejecutadas en los más variados tipos de materiales, realizada para el Shopping Center Recife en su Parque de Esculturas dedicado a la exposición de obras representativas de artistas pernambucanos al público visitante de este sitio. Destácanse entre las obras restauradas las de Francisco Brennand (Lêda e os cisnes), Christina Machado (O Beijo), Ferreira (O Pássaro), Corbiniano (Mulher Negra), José Paulo (O Pensador), Cavani Rosas (Caboclo de Lança), Nicole (Anjos), Miguel dos Santos (Guerreiro) del conjunto de cerca de dos decenas de esculturas (MELO y VIEIRA, 2015).

De este modo vemos el trayecto de formación y trabajos de un artista contemporáneo, con diálogo entre los artistas pernambucanos y raíces en los fundamentos de la pintura y escultura de los Grandes maestros de la antigüedad y de la contemporaneidad. El 2014 se dedica a producir una serie de cuadros, litografías y esculturas en su lenguaje preferencial -Surrealismo-, produciendo un total de 14 obras en homenaje a Salvador Dalí. En este trabajo presentamos 02 (dos) de sus cuadros realizando una lectura estéticohomológica de dichos trabajos.

\subsection{La geometría proyectiva}

La geometría proyectiva estudia las propiedades geométricas que se obtienen por proyección central. Esta geometría (desarrollada por Poncelet) se basa en determinadas operaciones que se realizan sobre formas geométricas concretas, el estudio de diversas transformaciones y la introducción sistemática de los elementos geométricos situados en el infinito (ABAJO Y BENGOA, 2006). 
Con la geometría proyectiva se hace muy presente el concepto de infinito, y con él se deberán tener en cuenta los elementos impropios, aquellos situados en el infinito. Estos elementos son:

Punto impropio: Es el punto del infinito común de un conjunto de rectas paralelas. Cualquier recta tiene un único punto impropio.

Recta impropia: Es la recta del infinito común de un conjunto de planos paralelos. Cualquier plano tiene una única recta impropia.

Plano impropio: Es el conjunto de todas las rectas y puntos impropios.

En las proyectividades, dos formas de primera categoría son proyectivas si la razón doble de cuatro elementos de una de ellas es igual a la de sus puntos homólogos en la otra forma. Poncelet demostró que esta relación invariable calculada para la figura objeto mantéense en la figura imagen para estos mismos cuatro puntos a través de las operaciones fundamentales de proyectar e seccionar (MELO, 2009).

Una proyección consiste en hacer pasar por un elemento cualquiera una recta o plano que definirá la proyección del elemento sobre una superficie de proyección al intersecarla. Esta intersección o proyección se denomina sección.

Se puede proyectar desde un punto o una recta. Si proyectamos desde un punto, este se denomina centro de proyección. Si proyectamos desde una recta, esta se llamará recta de proyección. En ambos casos, por ellos pasarán todas las rectas y planos proyectantes.

Cuando proyectamos una recta $r$ desde el centro de proyección $s$ obtenemos la recta $r^{\prime}$, determinada por el plano que contiene a la recta $r$ y el centro s e interseca al plano de proyección en la recta r'.

Figura 8: proyección de una recta a partir del centro S.

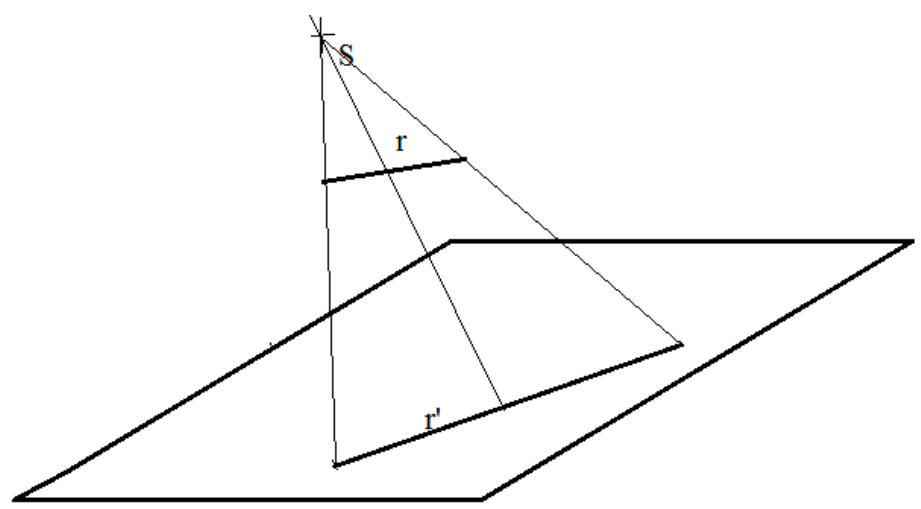

Fuente: autora, 2015.

Las homografías son transformaciones proyectivas que establecen una correspondencia entre elementos de la misma especie. Esto significa que a un punto le corresponde otro punto y a una recta le corresponde otra recta. Es la correspondencia punto a punto y recta a recta de dos figuras planas. 
Será necesario abatir en un mismo plano de representación los dos planos que conforman la homología. Este abatimiento se puede hacer uno sobre otro, quedando ambos planos a un lado del eje o abatiéndolos cada plano a un lado del eje (ABAJO Y BENGOA, 2006). Aunque esta geometría estudie las proyecciones de figuras tridimensionales sobre el plano bidimensional, es posible establecer las relaciones homológicas de figuras de un mismo soporte geométrico, sin embargo son figuras de espacios homológicos sobrepuestos e distintos proyectivamente hablando (MELO, 2009).

Para que dos figuras sean homológicas deberán cumplir dos condiciones. Son las mínimas exigibles para que podamos considerar una relación homológica entre figuras:

Un par de puntos homólogos alineados con el punto 0 , centro de la homología.

Un par de rectas homólogas que se corten en un punto del eje de la homología.

Son puntos dobles todos aquellos que sean homólogos de sí mismos. Todos los puntos dobles $\left(\mathrm{X}=\mathrm{X}^{\prime}, \mathrm{Y}=\mathrm{Y}^{\prime}, \mathrm{Z}=\mathrm{Z}^{\prime}\right)$ de una homología están situados en el eje de homología (e), tal como ocurre para los puntos de plano objeto $(A B C)$ y de la imagen $\left(A^{\prime} B^{\prime} C^{\prime}\right)$.

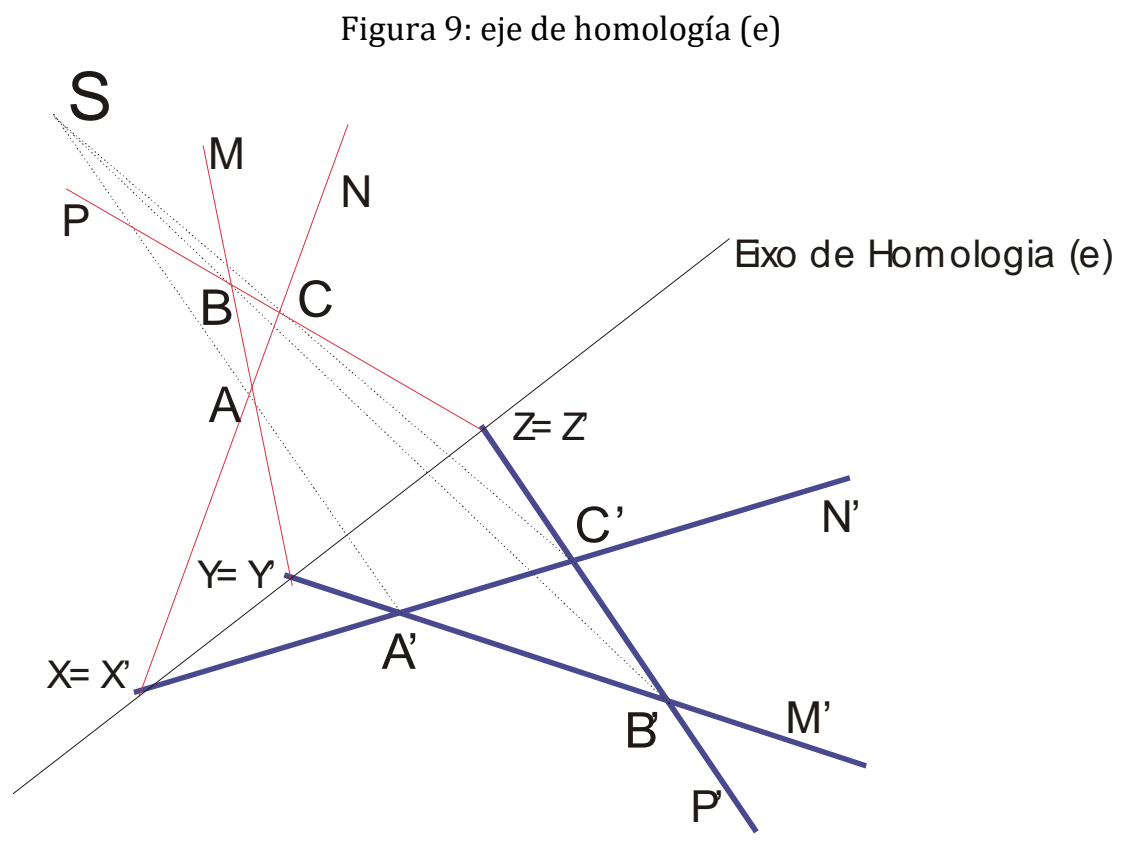

Fuente: autora, 2009.

Subrayamos el encuentro de los pares homólogos en el centro $\mathrm{S}$ (centro de homología) conforme el teorema de Desargues $^{2}$.

Rectas límites

\footnotetext{
2 Gérard Desargues (Lyon, 1591-1661) Matemático e ingeniero francés. Fue profesor en Paris y oficial del cuerpo de ingenieros. Ideó la geometría proyectiva y se interesó vivamente por las aplicaciones de la geometría a la arquitectura y a la ingeniería.
} 
Se tomáramos por el centro de radiación $\mathrm{S}$ un plano paralelo al plano objeto cortaremos el plano imagen en la recta límite que será f' (eje de Fuga) que corresponderá a la imagen de todos los puntos del objeto que están en el infinito (Figura 10).

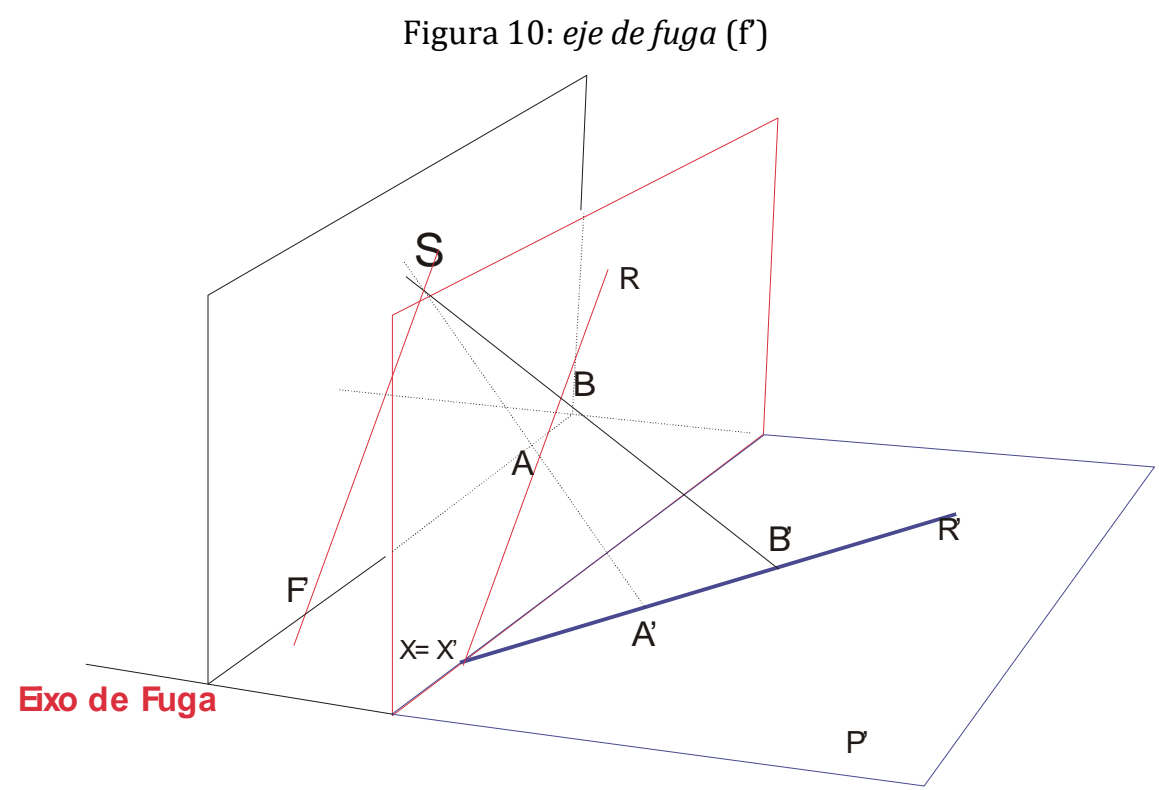

Fuente: autora, 2009.

Igual sucedería si trazamos por el centro $S$ un plano paralelo al plano imagen cortaremos el mismo en la recta d (eje de desvanecimiento) que corresponderá a los puntos del objeto que están en el infinito (figura 11).

Figura 11: eje de desvanecimiento

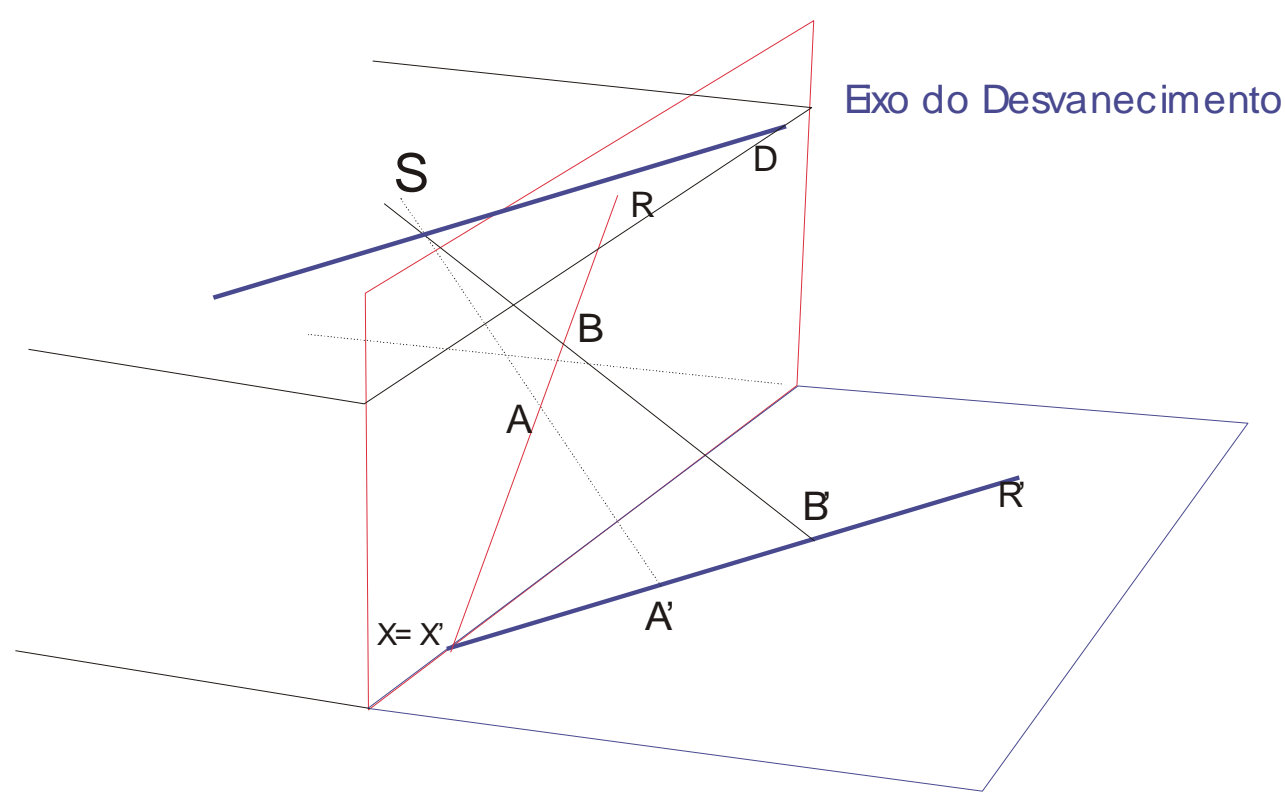

Fuente: autora, 2009. 
De tal modo que las rectas límites de una homología son el lugar geométrico de todos los puntos homólogos de los situados en el infinito del otro plano.

Como están generadas por un sistema de planos paralelos dos a dos, la distancia de una de ellas al eje es la misma que la distancia de la otra al centro de radiación, y viceversa. Y es por este motivo también que las rectas límite serán paralelas al eje. Ambas propiedades se mantendrán cuando el sistema este abatido y representado en el plano (ABAJO Y BENGOA, 2006; MELO, 2009).

\section{ANÁLISIS ESTÉTICO-HOMOLÓGICA DE LAS PINTURAS}

En este apartado mostraremos un análisis de dos cuadros del artista Marcos Carvalho de su homenaje al surrealismo de Dalí. Este artista busca un intercambio entre dos culturas (española y brasileña) a través de un mismo lenguaje, el lenguaje de la pintura. Dos hombres, de dos mundos distintos y a la vez iguales en su deseo de expresar su inconsciente usando el lenguaje del arte, el lenguaje del surrealismo.

Para hablar de la obra de arte hay que tener en cuenta elementos como el contexto, las ideas subyacentes, los iconos, la corriente a la cual la obra está insertada, pues existen como ya hablamos modelos distintos para un análisis profunda de una obra de arte. Podemos hacer una lectura factual subrayando los elementos como el color, la forma, o sea, un abordaje descriptivo. Aun podemos realizar una lectura técnica, donde destacamos los materiales usados en la ejecución de la obra sean óleo sobre lienzo, madera, aguada, etc. Además podemos elegir por ejemplo una lectura convencional que se apoya en convenciones socio-histórico-antropológicas (COSTELLA, 1997).

Primeramente, iremos tratar de la obra Volátil lembrança de um passado que ficou para trás (figura 12). En ella encontramos imágenes como la jirafa, la espalda femenina y el huevo. Ya presentamos con antelación el uso que hacía Dalí de estas imágenes como forma de expresar sus ideas del inconsciente. De su parte Carvalho hace uso de tales iconos, quizás representando la búsqueda por la belleza femenina pero efémera como la Marilyn de vidrio y la muchacha de espalda que jamás ve su faz y sí su propia espalda. Jamás podrá mirar la belleza.

Por su turno, la jirafa, elegante y a la vez deshaciéndose como la belleza que se desvanece con el tiempo. Es fuerte y altiva pero se encuentra en el mismo plano de la caracola, lenta que junto al rinoceronte, casi ciego, sigue en la vida sin dar-se cuenta que la vida pasa rápidamente. El huevo, igual que en Dalí, se encuentra sobre la cabeza del hombre que parece llorar sus propias penas, quizás ahí desde el vientre de la madre.

Figura 12: Volátil lembrança de um passado que ficou para tras. Acrílica sobre lienzo, 2014. 


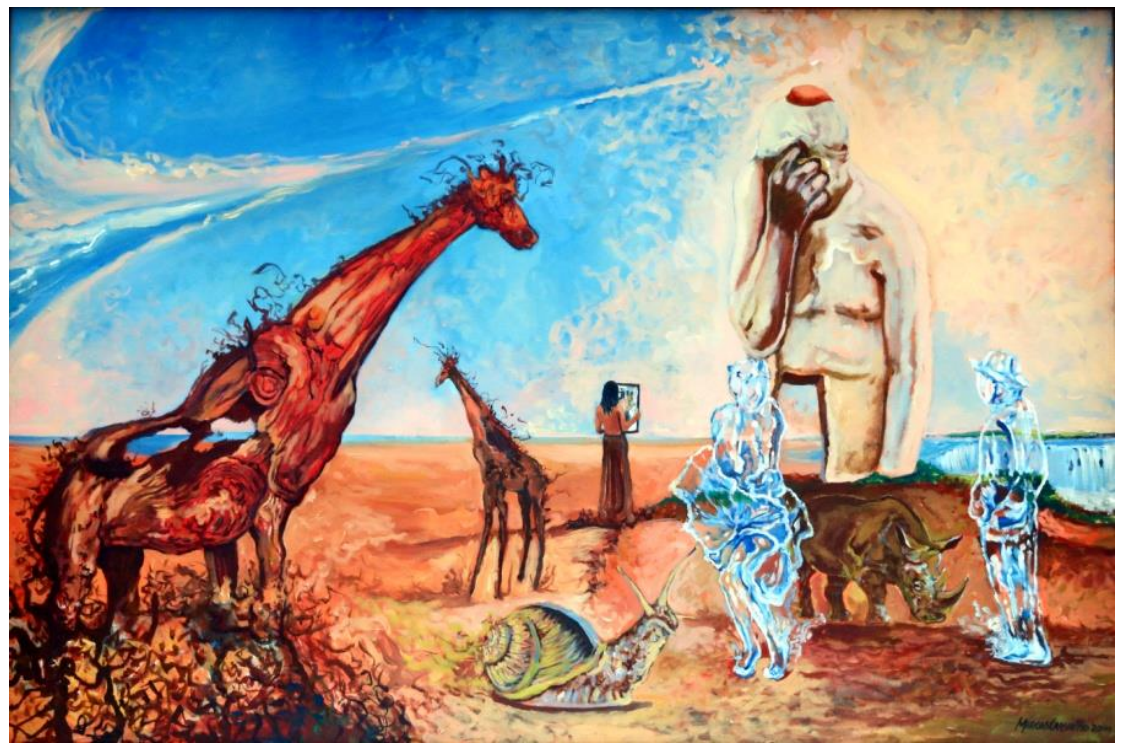

Fuente: Marcos Carvalho, 2014.

Los colores de esta obra están más cercanos a los colores usados por Dalí en algunos de sus trabajos. El azul, el marón, el blanco. El dibujo de las figuras es bastante académico respetando las proporciones aunque la jirafa se desfragmenta, como una madera que se corrompe.

Además de un análisis estético nos mueve el recto de realizar un análisis de la distribución de los elementos desde la geometría proyectiva, pues el límite de las formas en el espacio bidimensional del cuadro es obtenido por transformaciones proyectivas que a seguir nos proponemos a subrayar.

Figura 13: análisis homológico de Volátil lembrança de um passado que ficou para trás.

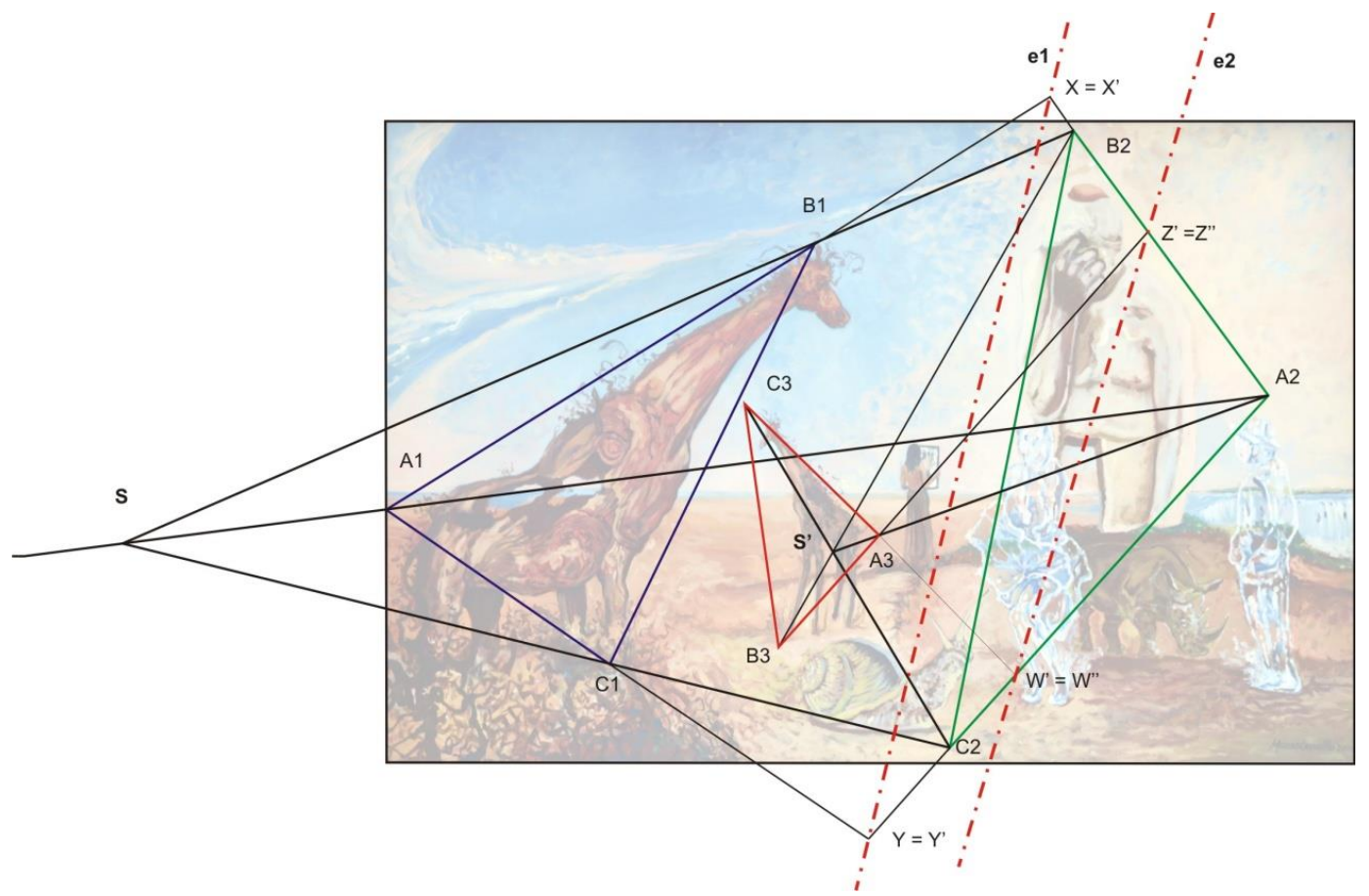

Fuente: autora, 2015. 
En la figura 13 vemos un producto de homologías. El área de la jirafa en el primer plano está delimitada por el triángulo A1B1C1 que es transformado homológicamente en el triángulo A2B2C2 que limita un espacio en el cuadro de figura efémera de Marilyn y del hombre con sus penas. En esta homología el centro de homología es $\mathrm{S}$ y el eje de homología es e1.

Dicho triángulo A2B2C2 es transformado homológicamente en A3B3C3 que limita la jirafa más pequeña en un tercer plano. En esta transformación encontramos el centro S' y el eje de homología e2.

El primer eje de homología (e1) divide el cuadro en dos áreas de equilibrio de la composición y tal como las reglas de la pintura existe una armonía entre estas dos áreas en la distribución de los elementos de peso. Aunque tengamos cuatro elementos cada uno de los lados, las imágenes de Marilyn y su admirador son translúcidas aliviando el peso y la tensión. El segundo eje de homología (e2), casi paralelo al primero, delimita con el eje e1 un área donde podemos observar una mayor intensidad de luz a través de los colores utilizados.

Además, este producto de homologías, comenzando por A1B1C1, pasando por A2B2C2 y siguiendo por A3B3C3 es el trayecto de entrada (mirada) de la composición. Por su peso, la jirafa en el primer plano es donde el observador inicia su trayecto de visión del cuadro. En seguida su visión es atraída por el hombre y sus penas. Finalmente su visión darse cuenta de la jirafa más pequeña en el tercer plano para finalizar en la muchacha de espalda en el centro del cuadro.

La intención del artista es pasar la idea de que todo es volátil. Las figuras en el lienzo presentan características que pueden ser interpretadas como figuras en formación o mismo en desfragmentación o fluidez.

La segunda obra elegida para el análisis es Dança do mel (Figura 14). En esta obra el artista tiene un lenguaje más cercano a su realidad cultural usando colores vibrantes y juntando el pájaro (colibrí) con las figuras humanas que solo se perciben como en niebla. El pájaro está rodeado de estas figuras casi mágicas que lo acompañan en el vuelo que es como la alegría del movimiento del vuelo y de los colores.

Figura 14: Dança do Mel. Acrílica sobre lienzo, 2014. 


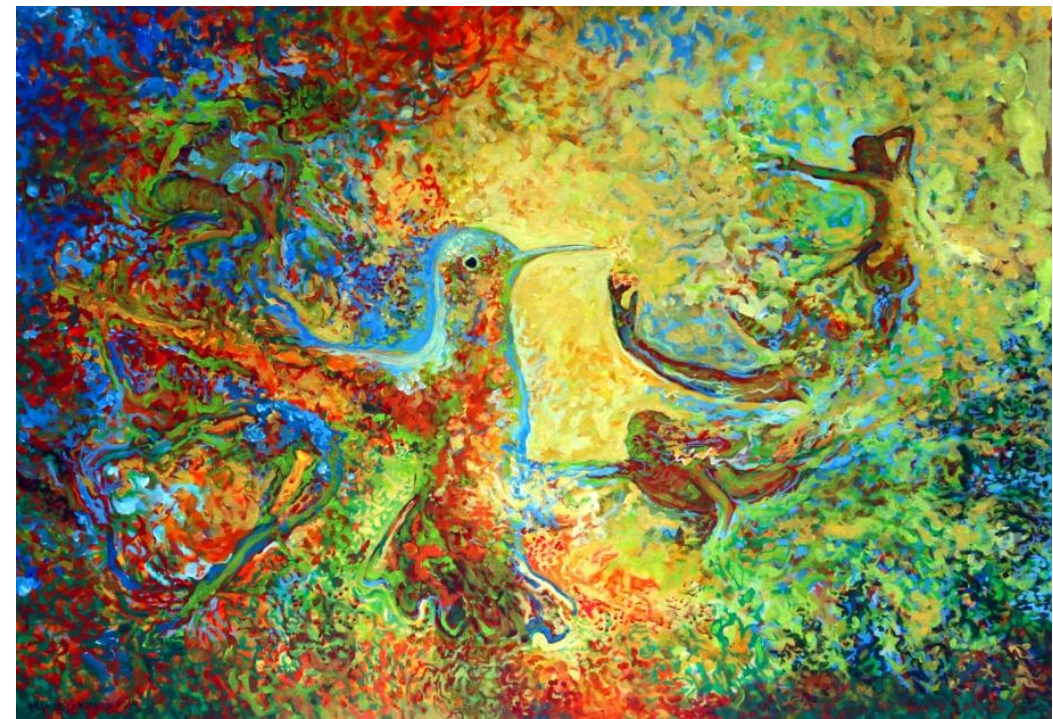

Fuente: Marcos Carvalho, 2014.

Mientras en el cuadro Sueño causado por el vuelo de una abeja alrededor de una granada un segundo antes de despertar de Dalí, una figura humana es rodeada por figuras de animales, el cuadro de Carvalho enseña la figura del pájaro rodeada por figuras humanas distorsionadas como en sueño.

En la figura 15 verificamos la presencia de un producto de homologías. La primera corresponde al triángulo A1B1C1 que delimita el colibrí y es transformado en el triángulo A2B2C2 que delimita el espacio de las figuras humanas que están en un segundo respecto al colibrí (figura central en el cuadro).

Figura 15: Dança do mel - analizado.

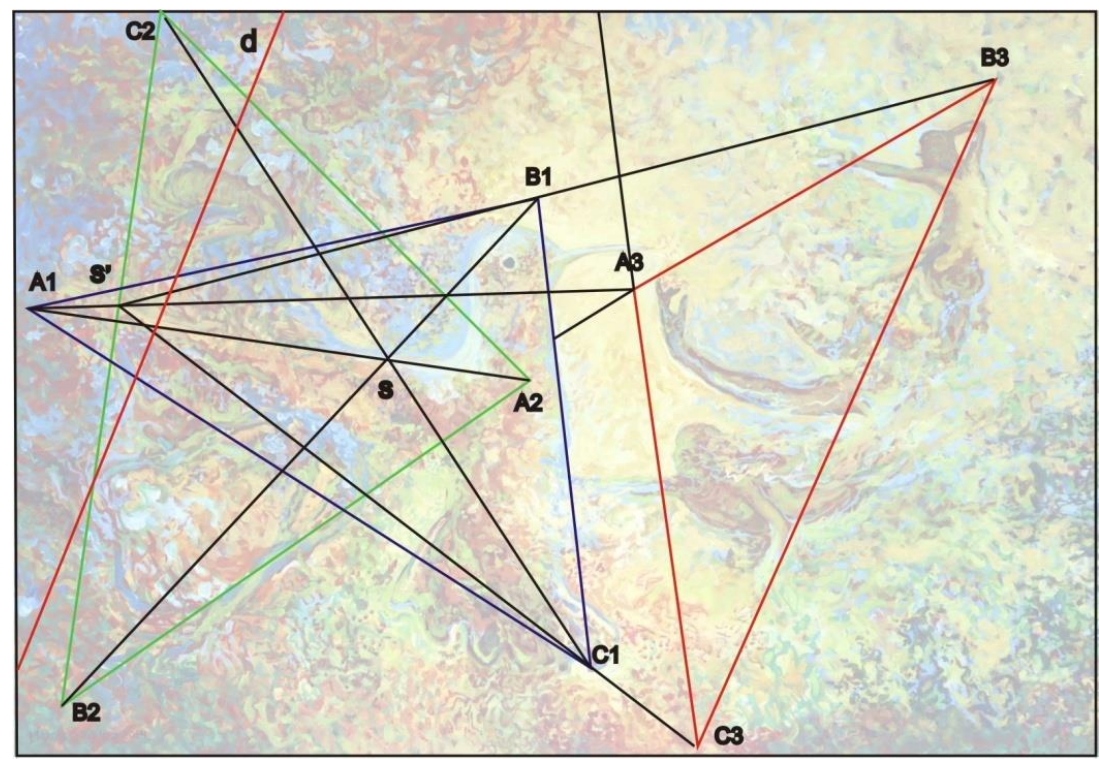

Fuente: autora, 2015.

El segundo producto corresponde al triángulo A1B1Ca y su homólogo A3B3C3 que delimita las figuras humanas que se encuentran en el lado 
opuesto respecto al colibrí y equilibran la composición. Destacamos en esta homología la presencia del eje límite para la imagen que corta la figura objeto (A1B1C1) y hace con que los pontos internos del objeto pasen a la posición externa en la imagen (A3B3C3).

El primero producto está al lado izquierdo del cuadro y mantienen el equilibrio de la composición en oposición al triángulo A3B3C3 de menor peso tal como dictan las reglas de equilibrio de la pintura más clásica.

Mirando el equilibrio estético de la composición podemos verificar que con el corte del eje límite en el primer triángulo se justifica en el área de mayor luz en el cuadro que está establecida a partir del vértice A3 para fuera del triángulo dando paso a una intensa luz que destaca la cabeza del colibrí principal elemento en la composición.

\section{CONCLUSIONES}

En estos dos caso presentados buscamos realizar un análisis que considerase no sólo los aspectos estéticos del cuadro sino que consideramos las bases homológicas de una lectura del equilibrio en dichas obras, hecho ya realizado por otros autores en otros artistas de otras corrientes de esta expresión humana que trata de representar los sentimientos del alma.

En estas lecturas homológicas vemos que estos aspectos geométricos acompañan las reglas de la pintura respecto al equilibrio, a la armonía entre formas y espacios, el uso del color como elemento para destaque de figuras o ideas.

Es interesante notar como el artista dialoga con las obras de Dalí a través de analogía u oposición con obras que destacamos en este artículo. De un lado, Carvalho usa la jirafa, el huevo, la espalda femenina, siguiendo las reglas académicas de proporción tal como Dalí, pero insertando aspectos de un arte surrealista personal. De otro lado, hace un contrapunto con la figura animal rodeada por las figuras humanas casi diluidas, al revés del cuadro Sueño causado por el vuelo de una abeja alrededor de una granada un segundo antes de despertar, donde la figura humana está rodeada por los animales.

Aun podemos notar que las pinceladas son diferentes y demuestran la personalidad propia de cada uno de los artistas. Un influenciado por colores y vivencias de su contexto (España, Europa), el otro por sus raíces sociales y culturales de un país de Sudamérica, Brasil, más precisamente de su ciudad Recife. Estos aspectos les modelan el carácter, el gusto, los elementos figurativos, los colores.

Finalmente, aunque el artista haga su trabajo de manera instintiva, permitiendo que hable su inconsciente, por tras de todo esto podemos darnos cuenta de una geometría que o acompaña y que nos sirve de base para una lectura geométrica, matemática que nos acerca arte y matemática. 


\section{REFERENCIA BIBLIOGRÁFICA}

ABAJO, F J R; BENGOA, V A. “Transformaciones Geométricas”, Dibujo Técnico II: $\mathbf{2}^{\mathbf{o}}$ Bachillerato. Editorial Donostiarra, 2006, p.37-58. ISBN: 978-84-7063-2990 .

ALARCÓ, P. Sueño causado por el vuelo de una abeja alrededor de una granada un segundo antes del despertar. Museo Thyssen - Bornemisza. Disponível em https://www.museothyssen.org/coleccion/artistas/dali-salvador/sueno-causadovuelo-abeja-alrededor-granada-segundo-antes. Consultado em 22 de outubro de 2017.

ALMEIDA, I; PINHO, L; MELO, S. "A Harmonia na obra da pintora Lícia Pinho". Anais do GRAPHICA 1994. Recife: UFPE, 1994.

ALMEIDA, B P. "El sueño como metáfora. La producción de lo imaginario en el surrealismo", EL SURREALISMO Y EL SUEÑO. Madrid: MUSEO THYSSENBORNEMISZA, p. 131-146, 2013.

BIBLIOTECA EL MUNDO. Los grandes genios del arte contemporáneo - El siglo XX - Dalí. Madri: Grupo Marte, 2006.

COSTElla, A F. Para Apreciar a Arte - Roteiro Didático. São Paulo: Editora Senac São Paulo, 1997.

CRUZ, A H L B; CAVALCANTI, R C. "Mondrian e a teoria homológica". Anais do Graphica 2009. Baurú-SP: Universidade Estadual Paulista - UNESP, 2009.

FRANÇA, C; BARBOZA, K; MELO, S. "A essência das formas". Anais do GRAPHICA 2003. Santa Cruz do Sul: Editoral Universitaria, 2003. 8 a 11 de setembro de 2003.

GALA, C. "De la parodia al patetismo: Lorca, Dalí y Buñel”, CAUCE - Revista de Filología y su Didáctica, n 22-23, 1999-2000, págs. 469-488.

LA VANGUARDIA. Dalí, un éxito de público 25 años después de su muerte. http://www.lavanguardia.com/cultura/20140122/54399424355/dali-el-controvertidogenio-que-a-los-25-anos-de-su-muerte-arrasa-en-taquilla.html. Consultado em 11 de abril de 2015.

MARIOTTI, M. A. La geometria in classe - Riflessioni sull'insegnamento della geometria. Bolonha: Editora Pitagora Bologna, 2005.

MELO, S. Transformações geométricas: isometrias, semelhanças, afinidades, projetividades. Recife: autora, 2009.

MELO, S (org.). Olhar a ponte que nos liga - Mirar el puente que nos une Marcos Carvalho. Recife: Editora Universitária da UFPE, 2016. 150 páginas. 
Publicação

online,

disponível

em: http://www3.ufpe.br/editora/ufpebooks/serie_extensao/olhar_a_pont/. ISBN 97885-415-0832-2.

MELO, S. S.; OLIVEIRA, H. A.; MOURA, R. M. A.; CUNHA NETO, M. F.; SILVA, R. A. S. DA; MARQUES, R. H. "El licenciando en Expresión Gráfica y su participación en ambientes no formales de educación" In: PRESENTE, PASADO Y FUTURO DE LA EXPRESIÓN GRÁFICA. 1 ED. CÓRDOBA AR: EDITORIAL DE LA FACULTAD DE ARQUITECTURA, URBANISMO Y DISENO DE LA UNIVERSIDAD DE CÓRDOBA, 2016, V.1, p. 374-378.

MELO, S. S.; FILHA, D. D. S. “Análisis estético-homológico para un aprendizaje significativo de la geometría proyectiva" In: Discutir el presente, forjar el futuro - Libro de actas. Río Cuarto: Unirio Editora, 2015, v.1, p. 339-345.

MELO, S de S; VIEIRA, G M. "A homologia presente na obra surrealista de Marcos Carvalho". GEOMETRIAS \& GRAPHICA 2015 PROCEEDINGS. Vol. 1, Cap. 2, p. 173-184. ISBN 978-989-98926-3-7.

MURADAS, I. M. Un modelo de valoración de obras de arte. Tesis doctoral, Departamento de Humanidades y Ciencias Sociales, Universidad de La Laguna, 1994-1995.

MUSEO NACIONAL CENTRO DE ARTE - REINA SOFIA. Dalí. Todas las sugestiones poéticas y todas las posibilidades plásticas. Madri: Ministerio de Educación, Cultura y Deporte, 2013.

NEVES JR, C A; MELO, S de S. "Mc Escher e a teoria homológica". Anais do Graphica 2013. Florianópolis- SC. 03 a 05 de novembro de 2013.

THE DALÍ MUSEUM. Eggs on the Plate without the Plate - Salvador Dalí. Disponible en http://archive. thedali.org/mwebcgi/mweb.exe?request=record;id=86;type=101. Consultado em 22 de outubro de 2107.

TV ESCOLA - TV CULTURA. Arte \& Matemática: Do Zero ao Infinito. Documentário sobre a relação das artes com a matemática. Realização TV Cultura e TV Escola. 2002.

VALCUBERO, A. "Una aproximación metodológica en el análisis de las obras de arte". Arte, individuo y sociedad, 22.2: 63-72, 2010. 